\title{
Article \\ Silencing an E3 Ubiquitin Ligase Gene OsJMJ715 Enhances the Resistance of Rice to a Piercing-Sucking Herbivore by Activating ABA and JA Signaling Pathways
}

\author{
Yuebai Zhang ${ }^{1}$, Mengting Chen ${ }^{1}$, Shuxing Zhou ${ }^{1}$, Yonggen Lou ${ }^{1,2, *} \mathbb{C}$ and Jing Lu ${ }^{1, *}$ \\ 1 State Key Laboratory of Rice Biology \& Ministry of Agriculture Key Lab of Agricultural Entomology, \\ Institute of Insect Sciences, Zhejiang University, Hangzhou 310058, China; 11816019@zju.edu.cn (Y.Z.); \\ mtchen@zju.edu.cn (M.C.); 3090100232@zju.edu.cn (S.Z.) \\ 2 Hainan Institute, Zhejiang University, Sanya 572025, China \\ * Correspondence: yglou@zju.edu.cn (Y.L.); jing_lu@zju.edu.cn (J.L.); Tel.: +86-571-88982622 (Y.L.); \\ +86-571-88982084 (J.L.)
}

check for updates

Citation: Zhang, Y.; Chen, M.; Zhou, S.; Lou, Y.; Lu, J. Silencing an E3 Ubiquitin Ligase Gene OsJMJ715 Enhances the Resistance of Rice to a Piercing-Sucking Herbivore by Activating ABA and JA Signaling Pathways. Int. J. Mol. Sci. 2021, 22, 13020. https://doi.org/10.3390/ ijms222313020

Academic Editor: Zsófia Bánfalvi

Received: 29 October 2021

Accepted: 29 November 2021

Published: 1 December 2021

Publisher's Note: MDPI stays neutral with regard to jurisdictional claims in published maps and institutional affiliations.

Copyright: (c) 2021 by the authors. Licensee MDPI, Basel, Switzerland. This article is an open access article distributed under the terms and conditions of the Creative Commons Attribution (CC BY) license (https:// creativecommons.org/licenses/by/ $4.0 /)$.

\begin{abstract}
The RING-type E3 ubiquitin ligases play an important role in plant growth, development, and defense responses to abiotic stresses and pathogens. However, their roles in the resistance of plants to herbivorous insects remain largely unknown. In this study, we isolated the rice gene OsJMJ715, which encodes a RING-domain containing protein, and investigated its role in rice resistance to brown planthopper (BPH, Nilaparvata lugens). OsJMJ715 is a nucleus-localized E3 ligase whose mRNA levels were upregulated by the infestation of gravid $\mathrm{BPH}$ females, mechanical wounding, and treatment with JA or ABA. Silencing OsJMJ715 enhanced BPH-elicited levels of ABA, JA, and JA-Ile as well as the amount of callose deposition in plants, which in turn increased the resistance of rice to $\mathrm{BPH}$ by reducing the feeding of $\mathrm{BPH}$ and the hatching rate of BPH eggs. These findings suggest that OsJMJ715 negative regulates the BPH-induced biosynthesis of ABA, JA, and JA-Ile and that BPH benefits by enhancing the expression of OsJMJ715.
\end{abstract}

Keywords: rice; OsJMJ715; Nilaparvata lugens; herbivore-induced defenses

\section{Introduction}

To defend themselves from herbivorous insects, plants have developed sophisticated defensive mechanisms known as constitutive and inducible defenses [1,2]. The inducible defense starts with the perception of herbivore-associated molecular patterns and/or damage-associated molecular patterns, followed by the activation of an array of early signaling events, such as the increase in levels of cytosolic calcium ion, burst of reactive oxygen species (ROS), and activation of mitogen-activated protein kinase (MAPK) cascades. These early signaling events elicit defense-related signaling pathways mediated by phytohormones, which in turn lead to a global reconfiguration of transcriptome, proteome, and metabolome, thereby enhancing direct and/or indirect defenses of plants to herbivores [2]. These phytohormones mainly include jasmonic acid (JA), salicylic acid (SA), and ethylene (ET). Recently, other phytohormones, such as abscisic acid (ABA), gibberellic acids, cytokinins, and auxins, have also been reported to modulate herbivore resistance through synergistically or antagonistically interacting with JA signaling [3]. For instance, Vos et al. [4] found that in Arabidopsis thaliana, the activation of primed JA-regulated defenses in response to secondary herbivore attack is dependent on ABA signaling. In contrast, ABA has been shown to negatively regulate resistance to Hirschmanniella oryzae by inhibiting JA biosynthesis in rice (Oryza sativa) roots [5].

Ubiquitin $(\mathrm{Ub})$ is a polypeptide consisting of 76 amino acids, and its mediated proteolysis extensively exists in eukaryotes. The Ub-targeted proteins are first modified by a cascade of reactions catalyzed mainly by three enzymes involving $\mathrm{Ub}$-activating enzymes (E1), Ub-conjugating enzymes (E2), and Ub ligases (E3); then, the mono- or 
poly-ubiquitylated proteins are degraded by the $26 \mathrm{~S}$ proteasome system [6-8]. Among these enzymes, E3 ligases are responsible for determining substrate specificity [8]. In Arabidopsis and rice, more than putative 1500 and 1300 E3 ligase-encoding genes were predicted, respectively; these E3 ligases can be classified mainly into four subfamilies on the basis of their characteristic domains and catalytic mechanisms: HECT (homologous to E6-associated protein C-terminus), RING (really interesting new genes), U-Box, and CRLs (cullin-RING ligases) [8-10]. Unlike other subfamilies of E3 ligases, CRLs incorporate with other proteins to form a complex that binds to substrates [9].

$\mathrm{Ub}$-mediated proteolysis has been reported to play an important role in the defense response of plants to biotic and abiotic stresses by regulating the biosynthesis and signaling of defense-related phytohormones or other defense-related components [11,12]. In Arabidopsis, for instance, the CRL-type E3 ligase CRL1 is involved in the signaling of JA by forming the SKP1-CRL1-F-box (SCF) complex assembled with the F-box protein COI1 (SCFCOI1). This process causes the degradation of JAZ repressors and activates the transcription of JA-responsive genes [13]. Moreover, the U-Box-type E3 ligases PUB22/PUB23/PUB24 negatively regulate PAMP-triggered immunity by modulating the production of ROS and cell death [14], and PUB19 negatively regulates ABA and drought responses [15]. In addition, RING-type E3 ligases have also been reported to regulate plant resistance to diseases and abiotic stress [11]. The Arabidopsis RING-type E3, MIEL1, for example, has been shown to negatively modulate Pseudomonas syringae resistance by degrading MYB30, a positive regulator of hypersensitive cell death [16]. The overexpression of a RING-type E3 ligase gene OsBBI1 in rice elevates broad-spectrum resistance to the blast fungus Magnaporthe oryzae by modifying cell wall defense responses [17]. RING-type E3 ligases also influence ABA-mediated stress (such as drought and salt) responses by participating in the degradation of positive or negative regulators in ABA biosynthesis and signaling [18-20]. However, the role of RING-type E3 ligase in plant herbivore resistance and its underlying mechanisms remain largely unknown.

Jumonji C (JmjC) domain-containing proteins, which have been identified to be ubiquitous histone demethylases in plants, can be divided into eight subfamilies: KDM6/JMJD3, KDM5/JARID1, KDM4/JHDM3, KDM3/JHDM2, KDM2/JHDM1, PHF, JMJD6, and JmjC domain-only. The JmjC domain is known to catalyze histone lysine demethylation via an oxidative reaction that needs Fe (II) and $\alpha$-ketoglutarate $(\alpha-K G)$ as cofactors [21,22]. The occurrence of mutations in highly conserved cofactor-binding residues had led some to speculate that several JmjC proteins in Arabidopsis and rice are inactive histone demethylases $[21,23,24]$. Among them, JMJ24, a member of the Arabidopsis KDM3/JHDM2 subfamily, has been found unable to demethylate lysine 9 of histone H3 [24]. Interestingly, JMJ24 also contains two RING domains, and recent work by Deng et al. [25] has reported that JMJ24 directly interacts with and ubiquitinates a DNA methyltransferase, CHROMOMETHYLASE 3, indicating that JMJ24 has E3 ligase activity.

Rice, one of the most important grain crops in the world, suffers from many insect pests, including the piercing-sucking herbivore, brown planthopper $(\mathrm{BPH}$, Nilaparvata lugens). Previous studies have found that $\mathrm{BPH}$-induced defense responses in rice are regulated by a complex signaling network, which mainly includes MAPK cascades and pathways mediated by JA, SA, ET, and $\mathrm{H}_{2} \mathrm{O}_{2}$ [26-30]. However, whether RING-type E3 ligases are involved in the herbivore-induced defense responses of rice remains unclear.

To answer this question, we cloned a gene in rice, OsJMJ715, which contains a JmjC domain and a RING domain, and is induced by gravid BPH female infestation (according to transcriptome data in $\mathrm{Xu}$ et al. [31]). By combining molecular biology, biochemistry, and bioassays, we found that OsJMJ715 specifically localized into the nucleus and had ubiquitination activity. Moreover, OsJMJ715 negatively regulated the resistance of rice to $\mathrm{BPH}$ at least in part via inhibiting BPH-elicited ABA biosynthesis and callose deposition. These findings suggest that OsJMJ715 plays a crucial role in BPH-induced rice defenses. 


\section{Results}

\subsection{Isolating and Characterizing OsJMJ715}

By using RT-PCR, the full-length cDNA of the OsJMJ715, including an open reading frame (ORF) of $3172 \mathrm{bp}$, was obtained (Figure S1). On the basis of the deduced amino acid sequence, we found that OsJMJ715 contains a JmjC domain at the C-terminal (Figure S2), belonging to the $\mathrm{KDM} 3 / \mathrm{JHDM} 2$ group of JmjC protein family. Seeing that a lysine $(\mathrm{K})$ in $\alpha$-KG-binding sites was replaced by an alanine (A) (Figure S2), we realized that OsJMJ715 is probably an inactive histone demethylase, as predicted by Lu et al. [21]. To verify this hypothesis, we constructed the fusion protein containing glutathione S-transferase (GST) and jmjC domain of OsJMJ715 (GST::715 $5^{\mathrm{dem}}$ ) for an in vitro histone demethylation assay. Meanwhile, a jmjC domain of OsJMJ706 (a histone demethylase in rice) was used as a positive control. The results showed that in contrast to OsJMJ706, OsJMJ715 has no H3K9 demethylase activity (Figure 1A).

$\mathbf{A}$

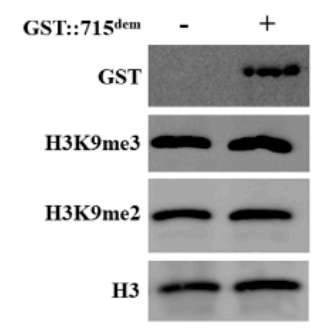

C
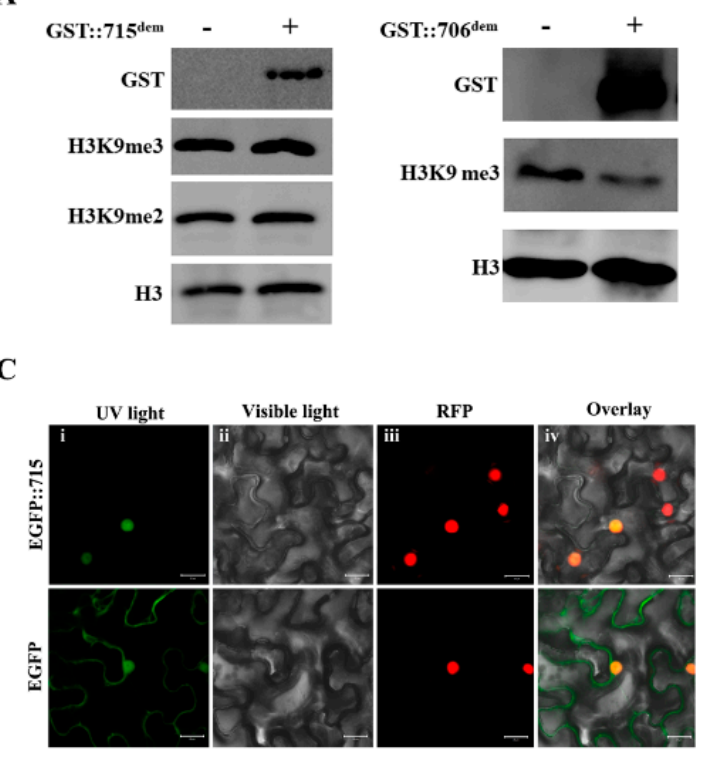

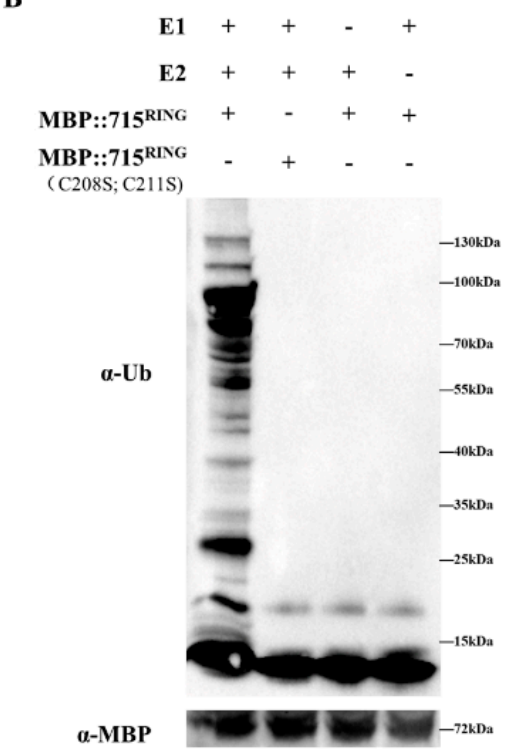

Figure 1. OsJMJ715 encodes a nucleus-localized RING-type E3 ubiquitin ligase. (A) In vitro histone demethylation assay of OsJMJ715. Bulk histone was incubated with (+) or without (-) GST::715 ${ }^{\text {dem }}$ (left) or GST::706 ${ }^{\mathrm{dem}}$ (right) fusion proteins in the reaction buffer for $2 \mathrm{~h}$ at $30^{\circ} \mathrm{C}$ and analyzed by immunoblotting by using anti-H3K9me2, anti-H3K9me3, anti-H3, and anti-GST antibodies. (B) In vitro ubiquitination assay of OsJMJ715. Fusion proteins of MBP::715 ${ }^{\text {RING }}$ and its mutant form MBP::715 RING (C208S; C211S) were assayed for E3 activity in the presence of E1, E2, and ubiquitin (Ub). Anti-Ub and anti-MBP antibodies were used to detect ubiquitinated proteins and fusion proteins, respectively. Molecular weight markers $(\mathrm{kDa})$ are shown on the right. (C) Subcellular localization of OsJMJ715. The EGFP::715 fusion protein and the EGFP protein were expressed in tobacco (Nicotiana benthamiana) leaves. Florescence assay was performed using a confocal microscopy. The photographs were taken in UV light, visible light, RFP, or in combination (overlay) (bar $=20 \mu \mathrm{m}$ ).

In addition to the JmjC domain, OsJMJ715 harbors a RING-finger domain at the Nterminal (Figure S2), which is known to function as ubiquitin E3 ligases [9]. To assess whether OsJMJ715 possesses E3 ligase activity, we expressed the RING domain of OsJMJ715 in Escherichia coli as a fusion with maltose-binding protein (MBP). In the presence of ubiquitin, E1 and E2, purified MBP::715 ${ }^{\text {RING }}$ was able to self-ubiquitinate, whereas MBP

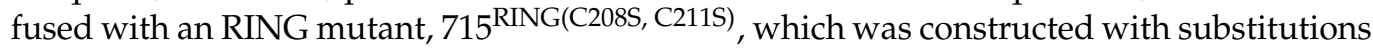
of Cys-208 and Cys-211 with Ser-208 and Ser-211 in the RING domain, was unable to produce ubiquitinated bands (Figure 1B). These findings suggest that OsJMJ715 has E3 ligase activity, and the intact RING domain is required. 
To elucidate the subcellular localization of OsJMJ715, we constructed an OsJMJ715::EGFP fusion gene, driven by a CaMV 35 S promoter (Figure S3), and transiently expressed the construct in Nicotiana benthamiana leaves. The result showed that OsJMJ715 specifically localized to the nucleus (Figure 1C). We further performed quantitative real-time PCR to analyze the expression profiles of OsJMJ715. As shown in Figure 2, the transcript level of OsJMJ715 increased in response to JA and ABA treatment $(24 \mathrm{~h}$ and $8-24 \mathrm{~h}$ after treatment, respectively), mechanical wounding ( $8 \mathrm{~h}$ after treatment), and BPH infestation (4-24 h), especially at a late stage, after these treatments. The data suggest that OsJMJ715 may help regulate rice-herbivore interactions.

A

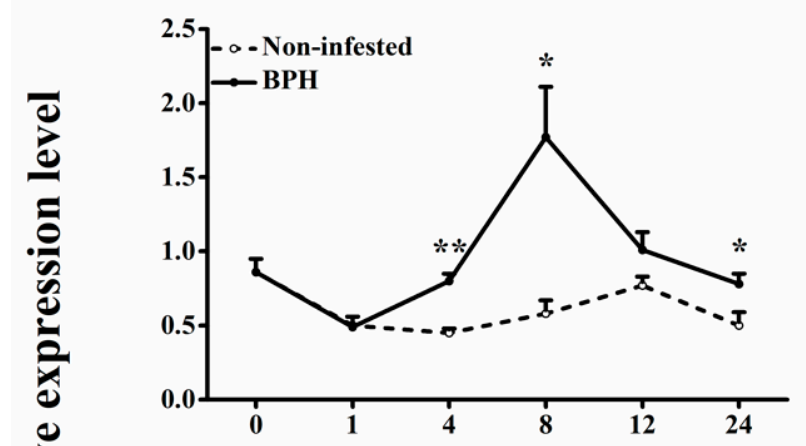

C

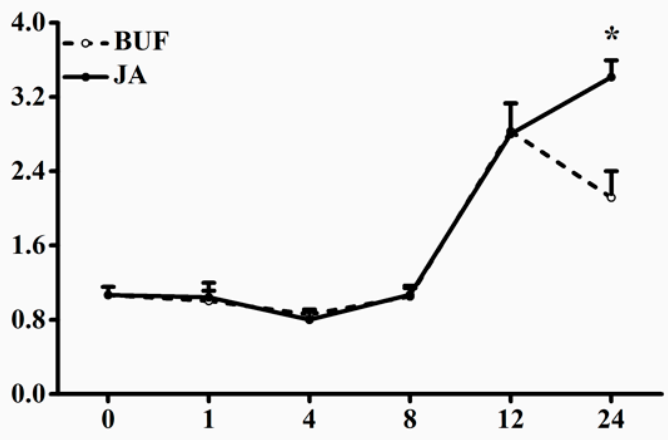

B

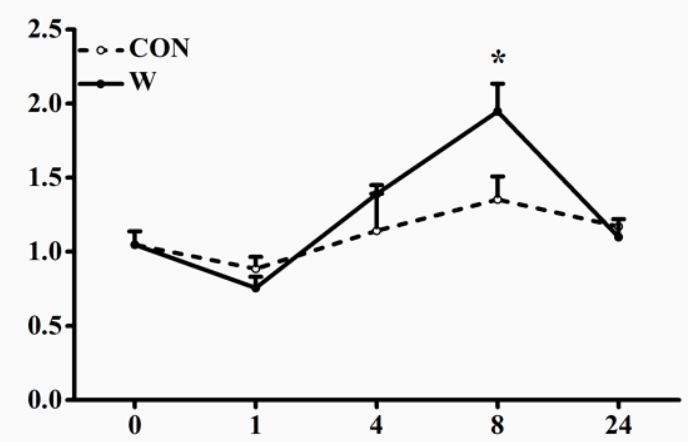

D

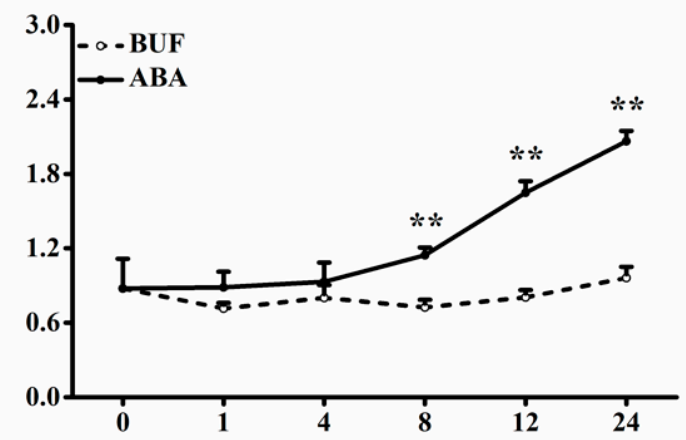

Time after treatment (h)

Figure 2. Expression profiles of OsJMJ715 in rice leaf sheaths after different treatments. Mean transcript levels $(+\mathrm{SE}, n=6)$ of OsJMJ715 in rice leaf sheaths that were infested by brown planthopper (BPH) (A), mechanically wounded (W) (B), or treated with JA (C) or ABA (D). BUF: buffer; CON: non-manipulated controls. Asterisks indicate significant differences between treatments and controls at time points $\left({ }^{*} p<0.05,{ }^{* *} p<0.01\right.$, Student's $t$-tests).

\subsection{Silencing OsJMJ715}

To study the function of OsJMJ715 in the herbivore-induced rice defenses, we constructed OsJMJ715-RNAi transgenic plants, and obtained two independent $\mathrm{T}_{2}$ homozygous $\operatorname{ir} J M J$ lines (R9 and R10) containing a single insertion (Figure S4). Transcriptional analysis showed that wounding-induced mRNA levels of OsJMJ715 in R9 and R10 lines were only $47.3 \%$ and $42.3 \%$ of those in WT plants (Figure 3A). No obvious differences in growth phenotypes were observed between WT and transgenic lines (Figure 3B). Moreover, the shoot height, root length, seed size, and mass of R9 and R10 plants were all similar to those of WT plants (Figure 3C-F).

\subsection{Silencing OsJMJ715 Enhanced the Resistance of Rice to BPH}

To evaluate the effect of silencing OsJMJ715 on the resistance of rice to $\mathrm{BPH}$, we performed a series of bioassays. BPH nymphs fed on irJMJ lines displayed similar survival rates and developmental durations to those fed on WT plants (Figure 4A,B). However, 
the amount of honeydew excreted by BPH female adults fed on R9 and R10 lines was significantly decreased, by $29.3 \%$ and $38 \%$, respectively, compared to those that fed on WT plants (Figure 4C). Moreover, the number of eggs laid by female adults that had emerged from irJMJ lines was less than that laid by female adults emerged from WT plants (Figure 4D). Silencing OsJMJ715 also reduced the hatching rate of BPH eggs: for eggs laid on R9 and R10, the hatching rate was only $55.2 \%$ and $66.1 \%$, respectively, of those laid on WT plants (Figure 4E). These results suggest that silencing OsJMJ715 enhances the resistance of rice to $\mathrm{BPH}$.

A

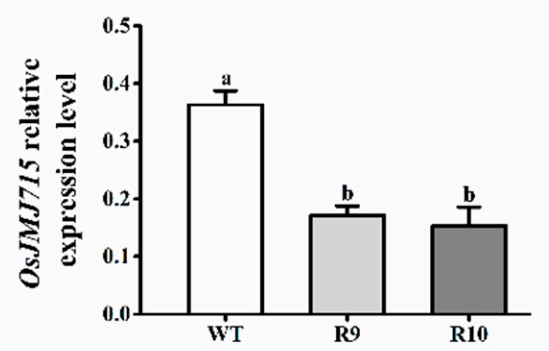

D

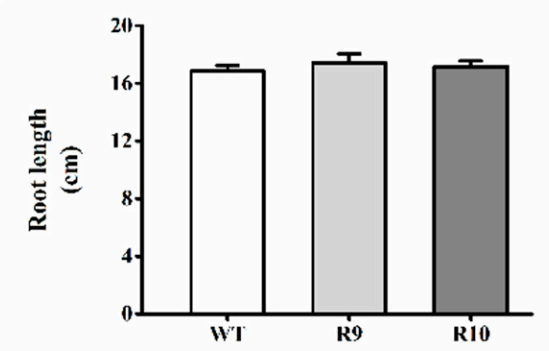

B

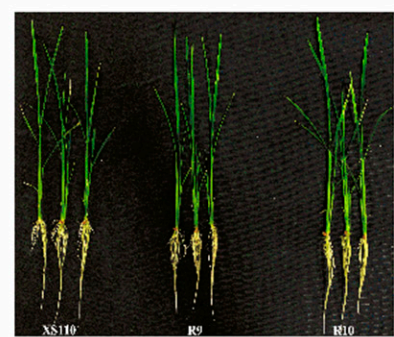

$\mathrm{E}$

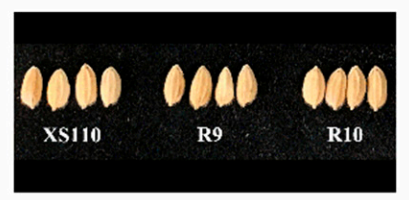

Line
C

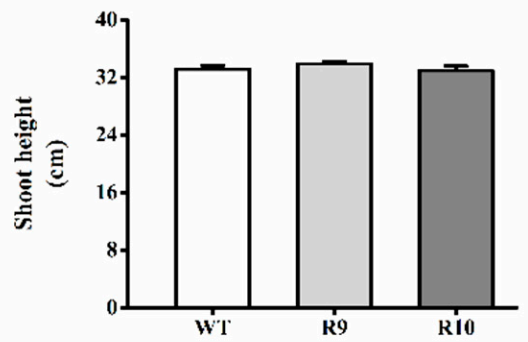

$\mathbf{F}$

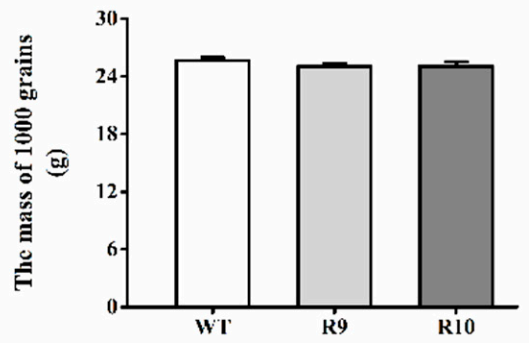

Figure 3. Silencing OsJMJ715 did not influence rice growth. (A) Mean transcript levels (+SE, $n=6)$ of OsJMJ715 in irJMJ lines and wild-type (WT) plants that were mechanically wounded for $8 \mathrm{~h}$. (B) Growth phenotype of 30-day-old irJMJ and WT plants. (C,D) Mean shoot height (C) and root length (D) $(+\mathrm{SE}, n=40)$ of 30-day-old irJMJ and WT seedlings. (E,F) Growth phenotype $(\mathrm{E})$ and mean weight $(+\mathrm{SE}, n=6)$ of seeds $(\mathbf{F})$ of irJMJ and WT plants. Different letters indicate significant differences among irJMJ and WT plants $(p<0.05$, Tukey's post hoc test).

\subsection{Silecing OsJMJ715 Enhanced BPH-Induced Levels of JA, JA-Isoleucine, and ABA}

To gain further insight into the mechanism underlying OsJMJ715-mediated rice resistance to $\mathrm{BPH}$, we measured levels of JA, JA-isoleucine (JA-Ile), and ABA in WT and irJMJ plants in response to gravid BPH female attack. As previously found [32], levels of JA and JA-Ile were induced quickly and continuously during gravid BPH female infestation (Figure 5A,B). Silencing OsJMJ715 did not influence the constitutive level of JA but slightly enhanced the constitutive level of JA-Ile (Figure 5A,B). Infestations by BPH caused the level of both JA and JA-Ile in irJMJ lines to rise, becoming significantly higher than that in WT plant 24 and 12-24 h, respectively, after its onset (Figure 5A,B). Gravid BPH female infestation also enhanced levels of ABA in both WT and irJMJ plants (Figure 5C). Silencing OsJMJ715 had no effect on constitutive levels of ABA, but it strengthened and quickened the response of $\mathrm{ABA}$ to $\mathrm{BPH}$ infestation-compared to that in non-infested plants, the level of ABA in BPH-infested plants began to significantly increase at $4 \mathrm{~h}$ after $\mathrm{BPH}$ attack in $\operatorname{irJMJ}$ lines at $24 \mathrm{~h}$ in WT plants; moreover, the BPH-infested level of ABA in irJMJ plants was always significantly higher than that in WT plants at 4-24 h after BPH infestation (Figure 5C). The data demonstrate that in plants silencing OsJMJ715 enhances the response of JA, JA-Ile, and ABA to BPH infestation. 
A

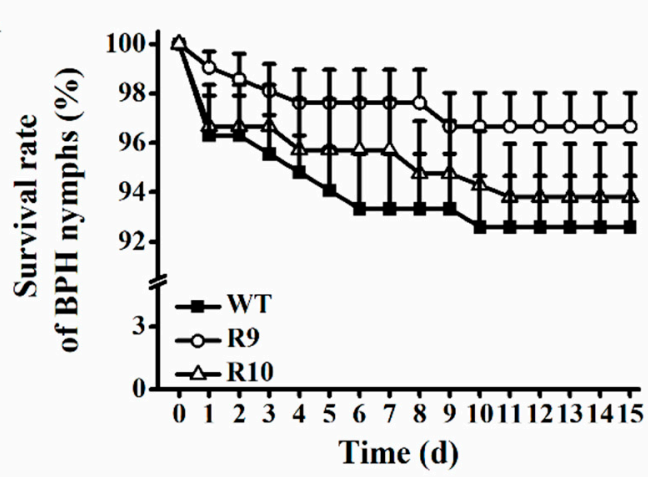

C

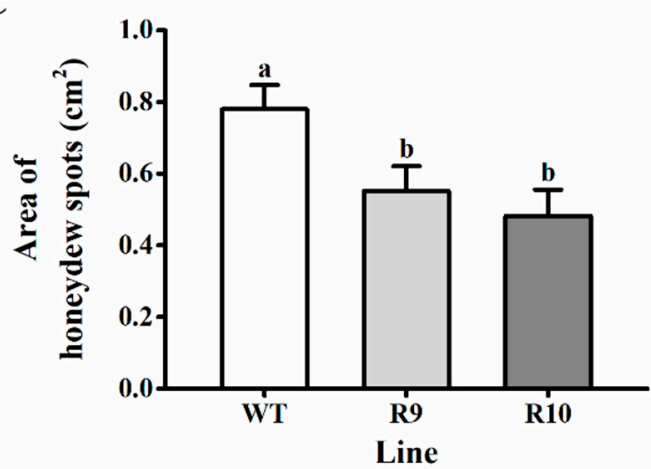

$\mathbf{E}$

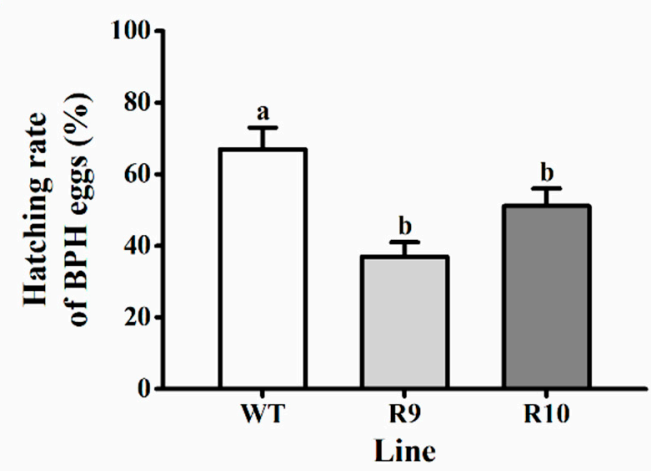

B

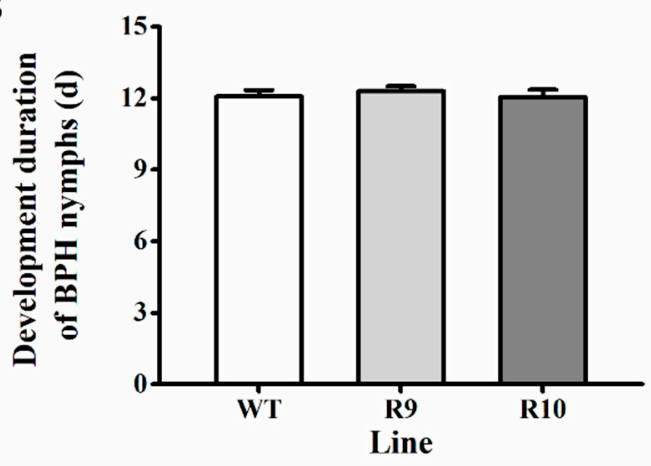

D

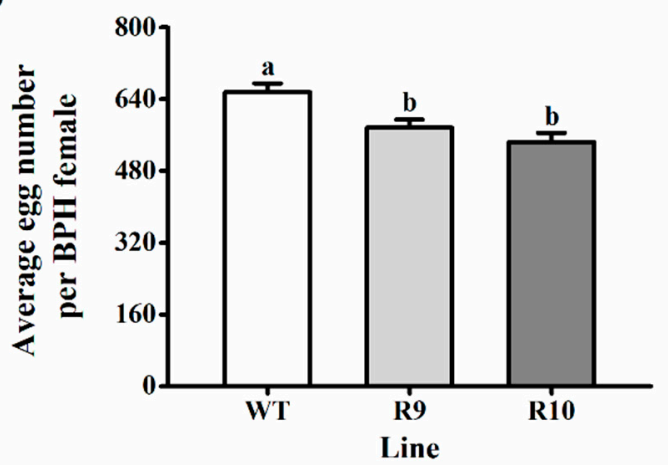

Figure 4. OsJMJ715 regulated rice resistance to brown planthopper (BPH). (A) Mean survival rate (+SE, $n=15$ ) of 15 newly hatched BPH nymphs that fed on irJMJ or wild-type (WT) plants within 15 days. (B) Mean developmental duration (+SE, $n=15$ ) of BPH nymphs that fed on irJMJ or WT plants. (C) Mean area of honeydew per day ( $+\mathrm{SE}, n=10)$ excreted by a BPH female adult that had emerged from ir $J M J$ or WT plants. (D) Mean number of eggs $(+\mathrm{SE}, n=20)$ laid by a BPH female adult that had emerged from irJMJ or WT plants. (E) Mean hatching rate $(+\mathrm{SE}, n=15)$ of BPH eggs on irJMJ or WT plants. Different letters indicate significant differences among irJMJ and WT plants $(p<0.05$, Tukey's post hoc test).

\subsection{OsJMJ715 Negatively Mediated BPH-Elicited Callose Deposition}

Callose deposition in sieve plates is an important defense mechanism of rice plants to prevent BPH feeding [33]. To ask whether OsJMJ715 regulates callose deposition and thereby influences BPH feeding as stated above (Figure 4C), we investigated callose deposition in rice plants of different genotypes before and after $\mathrm{BPH}$ infestation. As previously reported [34,35], little callose was observed in non-infested plants (Figure 6A-C). Upon BPH attack for $48 \mathrm{~h}$, callose deposition had increased in both WT and irJMJ plants (Figure 6D-F); however, silencing OsJMJ715 enhanced the deposition of callose- the amount of callose deposition in R9 and R10 was 1.9- and 3.2-fold, respectively, of that in WT plants (Figure 6G). 
A

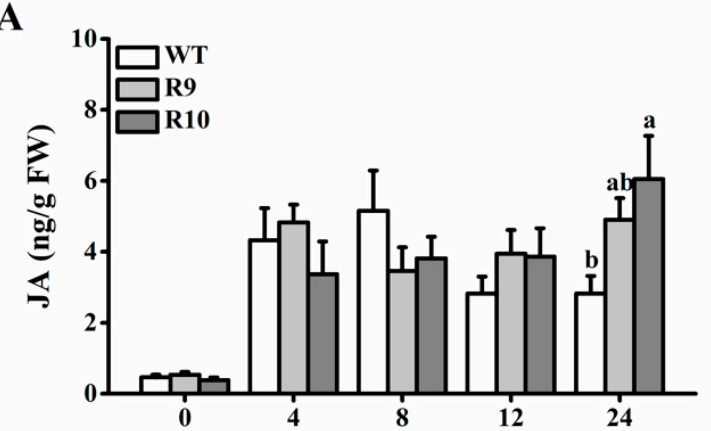

C

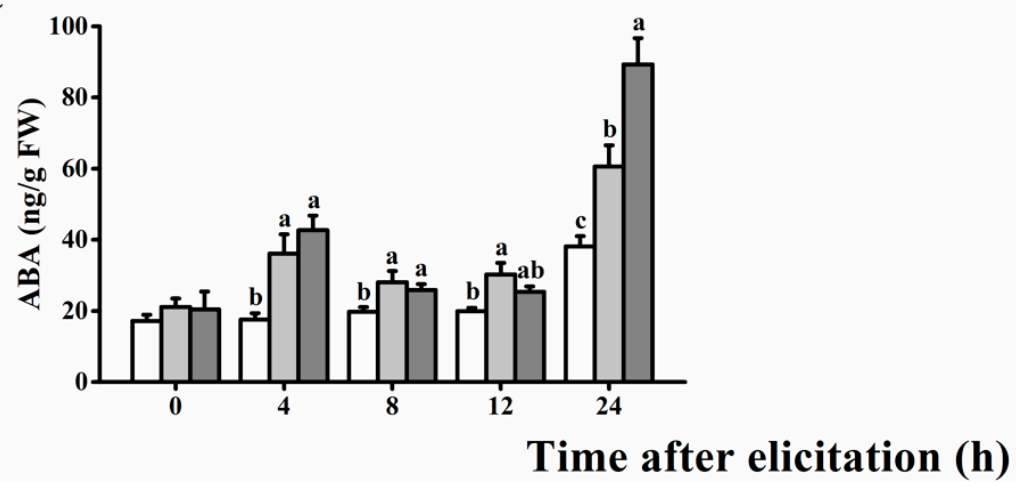

B

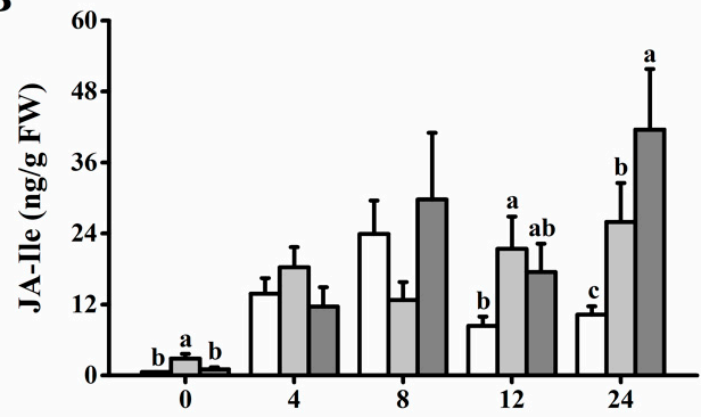

Figure 5. OsJMJ715 negatively mediated the brown planthopper (BPH)-induced accumulation of jasmonic acid (JA), JA-isoleucine (JA-Ile), and abscisic acid (ABA). Mean levels (+SE, $n=6)$ of JA (A), JA-Ile (B), and ABA (C) in irJMJ lines and wild-type (WT) plants that were infested by 10 gravid BPH females. Different letters indicate significant differences among $\operatorname{ir} J M J$ lines and wild-type (WT) plants at time points ( $p<0.05$, Tukey's post hoc test).
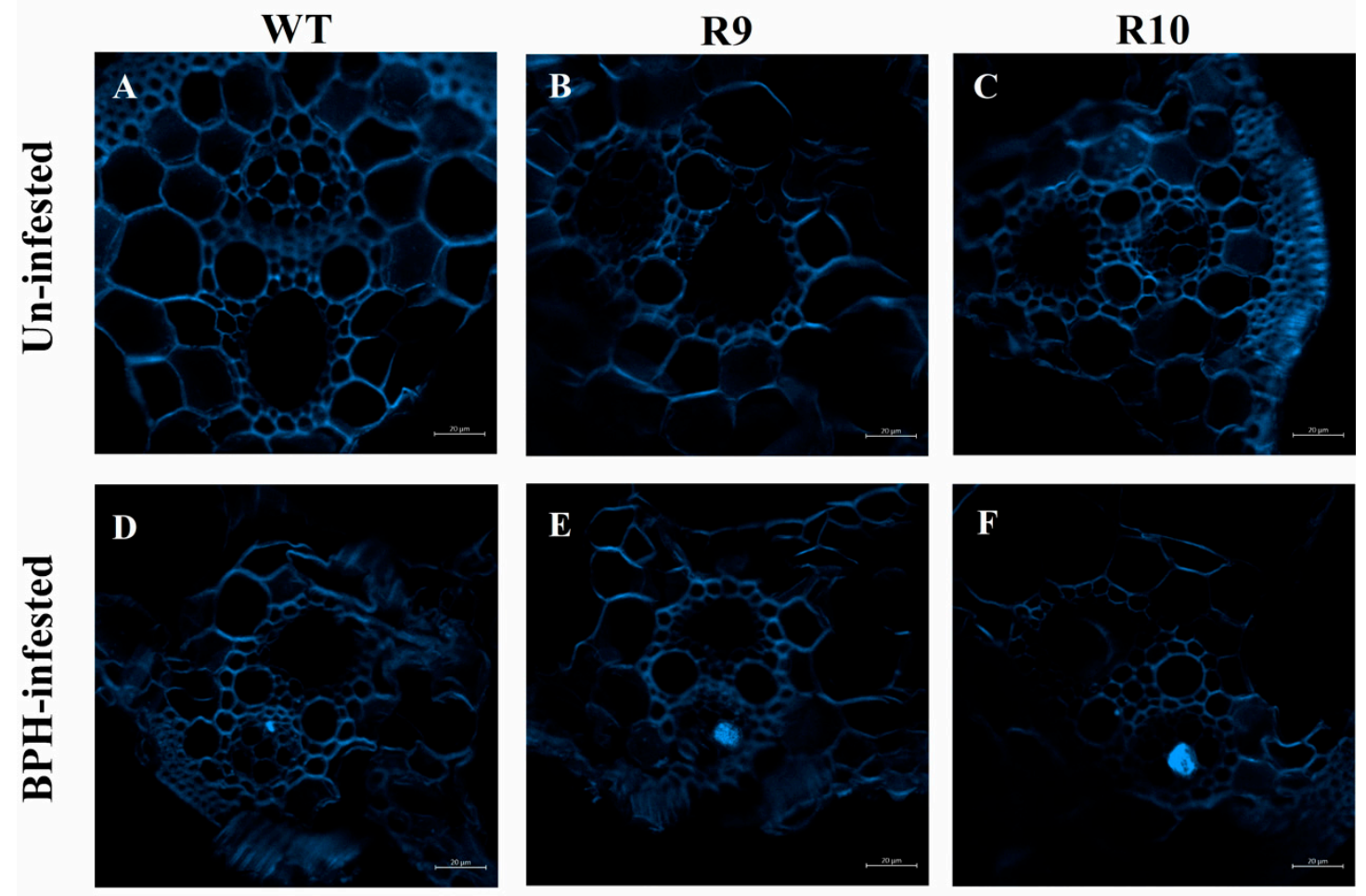

Figure 6. Cont. 


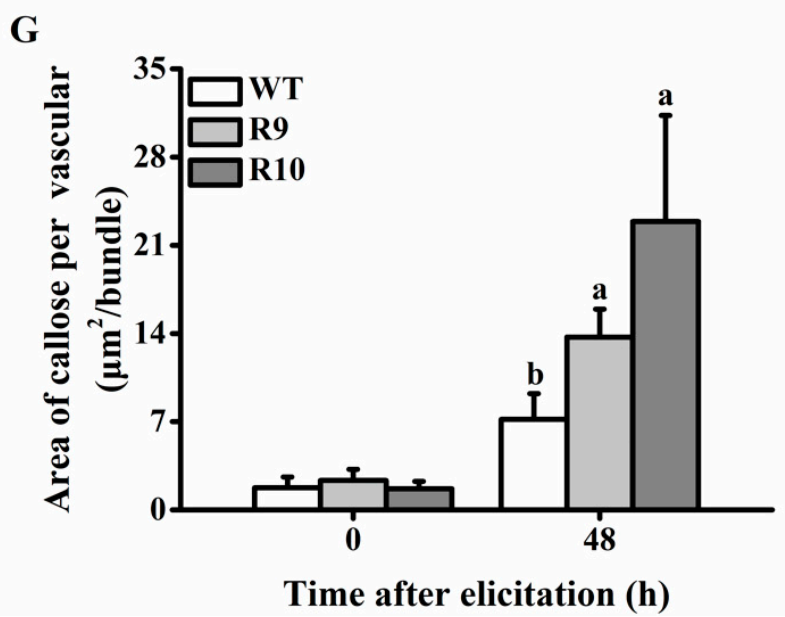

Figure 6. OsJMJ715 negatively mediated brown planthopper (BPH)-induced callose deposition. (A-F) Callose deposition in the vascular bundle in irJMJ lines and wild-type (WT) plants without (A-C) or with infestation by 10 gravid BPH females for $48 \mathrm{~h}$ (D-F). Bright blue fluorescence indicates callose deposition (bar $=20 \mu \mathrm{m})$. (G) Mean area $(+\mathrm{SE}, n=12)$ of callose per vascular bundle in irJMJ lines or WT plants that were infested by one gravid BPH females for $48 \mathrm{~h}$. Different letters indicate significant differences among irJMJ lines and WT plants at time points ( $p<0.05$, Tukey's post- hoc test).

\section{Discussion}

The RING-type E3 ubiquitin ligases play an important role in plant growth and development as well as in defense responses to abiotic stresses and pathogens. In this study, we found that a rice RING-type E3 ubiquitin ligase, OsJMJ715, plays an important role in regulating the resistance of rice to $\mathrm{BPH}$. Several lines of evidence support this statement. First, OsJMJ715 was induced by BPH infestation and mechanical wounding. Second, silencing OsJMJ715 enhances BPH-elicited accumulation of JA, JA-Ile, ABA, and callose, which subsequently reduces the hatching rate of BPH eggs and BPH feeding. Third, OsJMJ715 specifically localizes to the nucleus and has E3 ligase activity, suggesting that OsJMJ715 might be implicated in the degradation of proteins [36]. These data demonstrate that RING-type E3 ubiquitin ligase-mediated proteolysis is involved in regulating the resistance of plants to both pathogens [11,16-20] and herbivores (this study).

As stated in the introduction, RING-type E3 ubiquitin ligases have been reported to modulate phytohormone biosynthesis and signaling by degrading regulators in their processes. Here, we found that the expression of OsJMJ715 was induced by BPH infestation, and treatment with JA and ABA, whereas silencing OsJMJ715 enhanced BPH-induced levels of JA, JA-Ile, and ABA. This suggests that just as OsEBF1 attenuates OsLOX9 expression by degrading its transcriptional activator OsEIL1, decreasing JA accumulation in rice [37], OsJMJ715 may degrade activators in the biosynthesis of JA, JA-Ile, and ABA when plants were infested by BPH; as such, OsJMJ715 may function as a negative regulator in the biosynthesis of BPH-induced JA, JA-Ile, and ABA by forming a negative feedback loop with the level of JA, JA-Ile, and ABA. Such a negative regulator, like OsNPR1 [38], 9lipoxygenase (Osr9-LOX1) [39], OsWRKY53 [40], and MPK20-5 [41] reported previously in rice, may help ensure appropriate levels of JA, JA-Ile, and ABA in rice plants when infested by $\mathrm{BPH}$, thereby avoiding the autotoxicity that excessive plant defenses may lead to. Further studies should identify the targets of OsJMJ715 under BPH infestation to uncover the mechanism underlying the OsJMJ715-mediated regulation of defensive phytohormone biosynthesis.

We observed that silencing OsJMJ715 significantly reduced the amount of honeydew excreted by $\mathrm{BPH}$ and the hatching rate of $\mathrm{BPH}$ eggs. Given a significant increase in levels of $\mathrm{BPH}$-induced $\mathrm{ABA}$ in irJMJ plants, the above results suggest that ABA-mediated signaling pathway may play an important role in enhancing the resistance of rice to BPH. In addition to its contributions to plant disease resistance by controlling stomatal closure and callose deposition [42,43], the ABA-mediated signaling pathway has also been reported to regulate 
the resistance of plants to piercing-sucking herbivores, including $\mathrm{BPH}$, by influencing the callose deposition on plant sieve plates, a mechanism by which plants effectively prevent piercing-sucking herbivores from ingesting phloem sap [33,44]. For instance, Zhou et al. [35] found that silencing the ABA hydrolase gene, OsABA8ox3, remarkably increased endogenous levels of $\mathrm{ABA}$ and callose deposition in rice, which in turn enhances the resistance of rice to $\mathrm{BPH}$. Moreover, exogenous ABA increases the resistance of rice to $\mathrm{BPH}$ by promoting callose deposition, whereas resistant varieties that were treated with fluridone exhibit susceptibility to BPH with reduced callose deposition [45]. In addition to ABA-mediated signaling pathway, JA-mediated signaling pathway also plays an important role in modulating the resistance of rice to $\mathrm{BPH}$ by regulating the production of defensive compounds $[26,31]$. Thus, JA and ABA signaling pathways, both of which were strengthened in irJMJ plants compared to WT plants, might contribute to the enhanced resistance of irJMJ plants to $\mathrm{BPH}$.

Some defensive compounds in rice against BPH have been reported. Callose deposition on sieve plates, for example, as stated above, inhibits BPH feeding [34,35,46]. Some flavonoids and phenolamides, such as sakuranetin, $p$-coumaroyl putrescine, feruloyl putrescine, and cinnamoyl putrescine, also affect the survival and development of $\mathrm{BPH}$ [47-49]. Although no ovicidal compounds for BPH eggs have been identified, benzyl benzoate in japonica rice has been demonstrated to have a lethal role on the eggs of the white-backed planthopper Sogatella furcifera [50]. Moreover, Zhou et al. [51] recently revealed that feeding on plants treated with benzyl benzoate decreases the fecundity of $\mathrm{BPH}$ female adults. We found that silencing OsJMJ715 enhanced the accumulation of callose deposition. Hence, the decrease in BPH feeding on irJMJ plants is at least in part related to the increase in callose deposition. We look forward to investigating whether other compounds are involved in influencing BPH feeding and which compounds are responsible for the decrease in the hatching rate of $\mathrm{BPH}$ eggs.

In summary, our results show that OsJMJ715, a RING-type E3 ligase, negatively regulates the biosynthesis of BPH-induced JA, JA-Ile, and ABA. BPH can benefit by inducing the expression of OsJMJ715, which subsequently decreases the level of BPH-induced ABA, JA, and JA-Ile, as well as the resulting defense responses in rice. These findings demonstrate that $\mathrm{BPH}$ reduces host plant resistance by regulating a RING-type E3 ligase.

\section{Materials and Methods}

\subsection{Plant Material and Growth Conditions}

The rice variety Xiushui 110 (XS110, japonica) and OsJMJ715-RNAi transgenic lines (using XS110 as the receptor variety) were used for this work. Water-soaked seeds were germinated in an incubator $\left(28 \pm 2{ }^{\circ} \mathrm{C}, 14 \mathrm{~h}\right.$ light, $10 \mathrm{~h}$ dark). Seven-day-old seedings were transplanted to a hydroponic box (length $\times$ width $\times$ height: $45 \times 30 \times 15 \mathrm{~cm}$ ) containing nutrient solution [52] and grown in a greenhouse $\left(28 \pm 2{ }^{\circ} \mathrm{C}, 14 \mathrm{~h}\right.$ light, $10 \mathrm{~h}$ dark, $50-60 \%$ relative humidity) for 2 weeks, then were transplanted into individual plastic pots (diameter $\times$ height: $8 \times 10 \mathrm{~cm}$ ) that were placed in the greenhouse. Seven days later, the plants were used for experiments.

The transgenic tobacco $(N$. benthamiana) plants expressing the red fluorescent protein RFP-H2B were used for subcellular localization of OsJMJ715 [53]. Seeds were sown in a seedling pot (diameter $\times$ height: $5 \times 8 \mathrm{~cm}$ ) filled with a peat/vermiculite/perlite mixture $(2: 1: 1, v / v / v)$ and grown in the greenhouse as mentioned above. Plants were watered weekly.

\subsection{Insects}

BPH colonies were originally obtained from rice fields in Hangzhou, Zhejiang province, China, and reared in a growth chamber $\left(26 \pm 2{ }^{\circ} \mathrm{C}, 14 \mathrm{~h}\right.$ light $)$ on seedlings of a rice variety TN1, which is susceptible to BPH. 


\subsection{Plant Treatments}

For the mechanical wounding treatment, leaf sheaths of individual plant shoots were pierced 200 times with a needle (diameter $0.32 \mathrm{~mm}$ ). Non-manipulated plants were used as controls. For BPH infestation, plants were individually confined in glass cylinders (diameter $4 \mathrm{~cm}$, height $8 \mathrm{~cm}$, with 48 small holes) into which $10 \mathrm{BPH}$ gravid females were placed (Figure S5). Plants with empty cylinders were used as controls. For JA or ABA treatment, plants were grown in nutrient solution, and JA or ABA (Sigma-Aldrich, St. Louis, MO, USA) was added (first dissolved in a small volume of $70 \%(v / v)$ ethanol) into the nutrient solution to give a final concentration of $100 \mu \mathrm{M}$. Control plants were grown in nutrient solution without JA and ABA but with an equal volume of $70 \%$ ethanol.

\subsection{Isolation and Characterization of OsJMJ715}

The full-length cDNA of OsJMJ715 was obtained by reverse-transcription PCR from total RNA isolated from BPH-infested leaf sheaths of XS110 plants. The primers $715^{\mathrm{ORF}}$-F1 and $715^{\mathrm{ORF}}$-R1 (Table S1) were designed based on the sequence of OsJMJ715 (accession number: Os03g31594). PCR-amplified fragments were cloned into the pEASY-Blunt Simple Vector (TransGen, Beijing, China) and sequenced (BioSune, Hangzhou, China).

Nucleotide sequence alignments were carried out using BLAST (https:/ /blast.ncbi. nlm.nih.gov/Blast.cgi; accessed on 20 December 2015). Protein domains were analyzed using SMART (http:/ / smart.embl-heidelberg.de/; accessed on 20 December 2015).

\subsection{Quantitative Real-Time PCR}

For RNA isolation, rice leaf sheaths were ground into fine powders in liquid nitrogen. Total RNA was isolated by the MiniBEST Plant RNA Extraction Kit (TaKaRa, Dalian, China). A total of $1 \mu \mathrm{g}$ of RNA was reverse-transcribed using the PrimeScript ${ }^{\mathrm{TM}}$ RT Master Mix (TaKaRa, Dalian, China). A quantitative real-time PCR assay was performed on a CFX96 $6^{\mathrm{TM}}$ Real-Time System (Bio-RAD, Hercules, CA, USA) using the TB Green ${ }^{\mathrm{TM}}$ Premix EX Taq ${ }^{\mathrm{TM}}$ II (Tli RNaseH Plus) (TaKaRa, Dalian, China). The rice actin gene OsACT (accession number: Os03g50885) was used as an internal standard to normalize cDNA concentrations in tested genes; primers used for qRT-PCR are provided in Table S2. Each treatment at each time point was replicated six times.

\subsection{Subcellular Localization}

The full-length open reading frame (ORF) of OsJMJ715 without the stop codon was amplified by primers $715^{\mathrm{ORF}}-\mathrm{F} 2$ and $715^{\mathrm{ORF}}$-R2 (Table S1). The PCR product was inserted into p1301-EGFP vector [27] using a pair of restriction endonuclease, SalI and BamHI, to fuse it with EGFP (enhanced green fluorescent protein), yielding the construct OsJMJ715::EGFP (Figure S3). The construct was then transferred into Agrobacterium tumefaciens strain EHA105 competent cells, yielding a transformation vector. The vector was introduced into $N$. benthamiana leaves for transient expression as described in Huang et al. [53]. Tobacco leaves were cut into small pieces for fluorescence analysis at $24 \mathrm{~h}$ after agroinfiltration. The fluorescent signals were detected under a laser scanning confocal microscope (Zeiss, Oberkochen, Germany) as described by Huang et al. [53].

\subsection{Generation of Transgenic Plants}

A 382bp fragment of OsJMJ715 was amplified by primers $715^{\mathrm{RNAi}}-\mathrm{F} 1 / \mathrm{R} 1$ and $715^{\mathrm{RNAi}}$ F2/R2 (Table S1) and inserted into the pCAMBIA-1301 transformation vector to yield an OsJMJ715-RNAi interference construct (p1301-ir715, Figure S4). The construct was transferred into XS110 plants by using A. tumefaciens-mediated transformation. Homozygous lines of $\mathrm{T}_{2}$ generations were confirmed via GUS staining and PCR screening, as described in Zhou et al. [26]. Finally, two homozygous irJMJ lines (R9 and R10) harboring a single insertion of T-DNA were confirmed by Southern blot analysis were selected for further studies. 


\subsection{Histone Demethylation Assay}

The JmjC domains of OsJMJ715 and OsJMJ706 (accession number: Os03g31594) were amplified by primers $715^{\mathrm{dem}}-\mathrm{F} / \mathrm{R}$ and $706^{\mathrm{dem}}-\mathrm{F} / \mathrm{R}$ (Table S1), respectively [54]. Products were fused into the pGEX-4T-1 (GE Healthcare, Uppsala, Sweden) and then transferred into E. coli strain Transetta (DE3) (TransGen, Beijing, China). The recombinant proteins were purified by Glutathione Sepharose 4 Fast Flow (GE Healthcare, Uppsala, Sweden) according to the manufacturer's instructions. An in vitro histone demethylation assay was performed as previously described by Whetstine et al. [55]. After the reaction, samples were analyzed by $10 \%$ SDS-PAGE followed by immunoblotting with anti-GST (GE Healthcare, Uppsala, Sweden), anti-H3, anti-H3K9me2, or anti-H3K9me3 antibodies (Abcam, Cambridge, UK).

\subsection{Ubiquitination Assay}

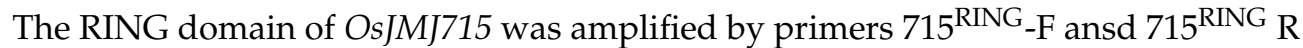
(Table S1). The RING domain mutant, $715^{\mathrm{RING}(\mathrm{C} 208 \mathrm{~S}, \mathrm{C} 211 \mathrm{~S})}$, was constructed with substitutions of Cys-208 and Cys-211 with Ser-208 and Ser-211 in the RING domain using two rounds of overlapping PCR with primer pairs $715^{\mathrm{RING}}-\mathrm{F} / 715^{\mathrm{C} 208 \mathrm{~S}}-\mathrm{R}, 715^{\mathrm{C} 208 \mathrm{~S}}-\mathrm{F} / 715^{\mathrm{RING}}-\mathrm{R}$ (first round) and $715^{\mathrm{RING}_{-}}-\mathrm{F} / 715^{\mathrm{C} 211 \mathrm{~S}}-\mathrm{R}, 715^{\mathrm{C} 211 \mathrm{~S}}-\mathrm{F} / 715^{\mathrm{RING}}-\mathrm{R}$ (second round, Table S1). All of PCR products were cloned into pMAL-c5X (NEW ENGLAND BioLabs, Ipswich, MA, USA). Fusion plasmids were transferred into E. coli Transetta (DE3). The recombinant proteins were purified by Amylose Resin (New England, BioLabs) according to the manufacturer's instructions. An in vitro ubiquitination assay was carried out as previously described in Xie et al. [56] and Zhang et al. [57]. A total of $20 \mathrm{ng}$ recombinant proteins

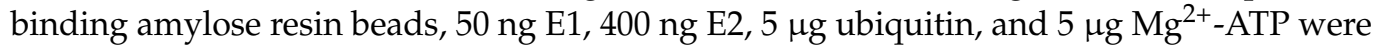
added to the reaction buffer containing $50 \mathrm{mM}$ Tris (pH 7.4), $2 \mathrm{mM} \mathrm{ATP,} 5 \mathrm{mM} \mathrm{MgCl}$, and $2 \mathrm{mM}$ DTT. The reaction mixture was incubated at $30^{\circ} \mathrm{C}$ for $2 \mathrm{~h}$ at $900 \mathrm{rpm}$ in a Thermomixer (Eppendorf, Hamburg, Germany). Reactions were stopped by adding loading buffer (Fdbio science, Hangzhou, China) and boiled for 8 min at $95{ }^{\circ} \mathrm{C}$. Samples were analyzed by $8-16 \%$ SDS-PAGE (Genscript, Nanjing, China), followed by immunoblotting using anti-ubiquitin or anti-MYB (Abcam).

\subsection{JA, JA-Ile, and ABA Measurement}

Plants of different genotypes were randomly assigned to $\mathrm{BPH}$ and control treatments. For JA, JA-Ile and ABA analysis, outer leaf sheaths of plants were harvested at 0, 4, 8, 12 and $24 \mathrm{~h}$ after treatment. Samples (about $150 \mathrm{mg}$ each) were ground in liquid nitrogen, compounds in each sample were extracted with $1 \mathrm{~mL}$ of ethyl acetate containing labeled internal standards $\left({ }^{2} \mathrm{D}_{2}\right.$-JA, ${ }^{2} \mathrm{D}_{6}$-JA-Ile and ${ }^{2} \mathrm{D}_{6}$ - $\left.\mathrm{ABA}\right)$ and analyzed by a Triple Quad liquid chromatography/mass spectrometry (Agilent Technologies, Santa Clara, USA) following the method described in $\mathrm{Lu}$ et al. [27]. Each treatment at each time point was replicated six times.

\subsection{Callose Measurement}

Rice plant shoots of different genotypes were individually confined within glass cylinders into which 10 gravid BPH females were placed. Then, $48 \mathrm{~h}$ later, outer leaf sheaths of the plants were collected, cut into $0.3-0.5 \mathrm{~cm}$ pieces, and immersed in $10 \%$ glycerol. Leaf sheaths were embedded in optimal cutting temperature compound (SAKURA, Torrance, CA, USA) and then cut into $10 \mu \mathrm{m}$ thick slices via a microtome (Thermo, Waltham, MA, USA) and subsequently placed into $95 \%$ ethanol for overnight. Slices were soaked with $1 / 15 \mathrm{M}$ phosphate buffer ( $\mathrm{pH} 7.0)$ for $30 \mathrm{~min}$, and then stained with $0.1 \%(w / v)$ aniline blue for $60 \mathrm{~min}$. Samples were observed and photographed using a laser scanning confocal microscope (Zeiss) as described by Yang et al. [58]. Callose deposition area was analyzed by Image-Pro Plus (version 6.0). The callose deposition area of each bundle was calculated with 12 replicates for each treatment. 


\subsection{Herbivore Bioassays}

To evaluate the effect of OsJMJ715 on the performance of BPH, we individually confined plants of wild-type (WT) and irJMJ lines in cylinders into which 15 newly hatched $\mathrm{BPH}$ nymphs were released. The number of surviving nymphs and newly emerged adults on each plant were observed and recorded every day until all the nymphs had become adults. Each treatment was replicated 15 times. The newly emerged adults were then paired (one female with one male) and introduced into a new plant of the same genotype as they emerged. Fourteen days later, the number of BPH eggs in individual plants was counted under a microscope. The experiment was replicated 20 times. We also measured the amount of honeydew excreted by individual newly emerged BPH female adults using a method described in Paguia et al. [59]. Briefly, rice plant shoots were individually confined within transparent plastic cups (diameter $9 \mathrm{~cm}$, height $12 \mathrm{~cm}$ ) that were placed on plastic Petri dishes lined with filter paper (Figure S6). Individual newly emerged BPH female adults from different rice genotypes were released into the cups and allowed to feed for $24 \mathrm{~h}$. The filter papers were collected and sprayed with a $0.1 \%$ ninhydrin in acetone solution [46] and then dried for $30 \mathrm{~min}$ at $60^{\circ} \mathrm{C}$. The area of the ninhydrin-positive deposition was measured with Image-Pro Plus. Each treatment was replicated 10 times. On the basis of these experiments, we calculated the survival rate and developmental duration of $\mathrm{BPH}$ nymphs, the fecundity of BPH female adults, and the amount of honeydew excreted by $\mathrm{BPH}$ female adults on plants of WT and irJMJ lines.

To investigate the influence of OsJMJ715 on the hatching rate of BPH eggs, we individually infested plants of different genotypes by 10 gravid BPH female adults using the method above. Then, $24 \mathrm{~h}$ later, BPHs were removed. The number of newly hatched neonates was recorded every day until no neonates emerged for three days in a row. The number of unhatched eggs was counted under a microscope to calculate the hatching rate of BPH eggs. Each treatment was replicated 15 times.

\subsection{Data Analysis}

Differences between two comparisons were analyzed by Student's $t$-tests. Multiple comparisons were analyzed by one-way ANOVAs followed by Tukey's post hoc test. The normality of data was tested using the Kolmogorov-Smirnov test $(p<0.05)$, and the equality of error variances was tested by Levene's test $(p<0.05)$. In the case of non-normality and/or unequal variances, data were logarithmic-transformed before ANOVAs. All data analysis was carried out with IBM SPSS Statistics, Version 20, International Business Machines Corporation (Armonk, NY, USA).

Supplementary Materials: The following are available online at https:/ /www.mdpi.com/article/10 .3390/ijms222313020/s1.

Author Contributions: Conceptualization, J.L., Y.L., and Y.Z.; methodology, J.L., Y.L., and Y.Z.; validation, J.L., Y.L., and Y.Z.; formal analysis, J.L., Y.L., and Y.Z.; investigation, Y.Z., M.C., and S.Z.; data curation, Y.Z.; writing-original draft preparation, Y.Z.; writing-review and editing, J.L., Y.L., and Y.Z.; visualization, J.L. and Y.L.; supervision, Y.L.; project administration, Y.L.; funding acquisition, Y.L. All authors have read and agreed to the published version of the manuscript.

Funding: The study was jointly sponsored by the National Natural Science Foundation of China (31930091) and the earmarked fund for China Agriculture Research System (CARS-01-43).

Institutional Review Board Statement: Not applicable.

Informed Consent Statement: Not applicable.

Data Availability Statement: Not applicable.

Acknowledgments: We thank Shengen Xie and Guilan Dong for their help with plant growth and $\mathrm{BPH}$ rearing. We also thank Emily Wheeler for editorial assistance.

Conflicts of Interest: The authors declare no conflict of interest. 


\section{References}

1. Suzuki, N.; Rivero, R.M.; Shulaev, V.; Blumwald, E.; Mittler, R. Abiotic and biotic stress combinations. New Phytol. 2014, 203, 32-43. [CrossRef]

2. Schuman, M.C.; Baldwin, I.T. The layers of plant responses to insect herbivores. Annu. Rev. Entomol. 2016, 61, 373-394. [CrossRef] [PubMed]

3. Nguyen, D.; Rieu, I.; Mariani, C.; van Dam, N.M. How plants handle multiple stresses: Hormonal interactions underlying responses to abiotic stress and insect herbivory. Plant Mol. Biol. 2016, 91, 727-740. [CrossRef] [PubMed]

4. Vos, I.A.; Verhage, A.; Schuurink, R.C.; Watt, L.G.; Pieterse, C.M.; Van Wees, S.C. Onset of herbivore-induced resistance in systemic tissue primed for jasmonate-dependent defenses is activated by abscisic acid. Front. Plant Sci. 2013, 4, 539. [CrossRef] [PubMed]

5. Nahar, K.; Kyndt, T.; Nzogela, Y.B.; Gheysen, G. Abscisic acid interacts antagonistically with classical defense pathways in rice-migratory nematode interaction. New Phytol. 2012, 196, 901-913. [CrossRef]

6. Dreher, K.; Callis, J. Ubiquitin, hormones and biotic stress in plants. Ann. Bot. 2007, 99, 787-822. [CrossRef] [PubMed]

7. Santner, A.; Estelle, M. The ubiquitin-proteasome system regulates plant hormone signaling. Plant J. 2010, 61, 1029-1040. [CrossRef] [PubMed]

8. Adams, E.H.G.; Spoel, S.H. The ubiquitin-proteasome system as a transcriptional regulator of plant immunity. J. Exp. Bot. 2018, 69, 4529-4537. [CrossRef]

9. Vierstra, R.D. The ubiquitin-26S proteasome system at the nexus of plant biology. Nat. Rev. Mol. Cell Biol. 2009, 10, 385-397. [CrossRef]

10. Smalle, J.; Vierstra, R.D. The ubiquitin 26S proteasome proteolytic pathway. Annu. Rev. Plant Biol. 2004, 55, 555-590. [CrossRef] [PubMed]

11. Kelley, D.R.; Estelle, M. Ubiquitin-mediated control of plant hormone signaling. Plant Physiol. 2012, 160, 47-55. [CrossRef] [PubMed]

12. Miricescu, A.; Goslin, K.; Graciet, E. Ubiquitylation in plants: Signaling hub for the integration of environmental signals. J. Expr. Bot. 2018, 69, 4511-4527. [CrossRef] [PubMed]

13. Xie, D.X.; Feys, B.F.; James, S.; Nieto-Rostro, M.; Turner, J.G. COI1: An Arabidopsis gene required for jasmonate-regulated defense and fertility. Science 1998, 280, 1091-1094. [CrossRef]

14. Trujillo, M.; Ichimura, K.; Casais, C.; Shirasu, K. Negative regulation of PAMP-triggered immunity by an E3 ubiquitin ligase triplet in Arabidopsis. Curr. Biol. 2008, 18, 1396-1401. [CrossRef] [PubMed]

15. Liu, Y.C.; Wu, Y.R.; Huang, X.H.; Sun, J.; Xie, Q. AtPUB19, a U-box E3 ubiquitin ligase, negatively regulates abscisic acid and drought responses in Arabidopsis thaliana. Mol. Plant 2011, 4, 938-946. [CrossRef] [PubMed]

16. Marino, D.; Froidure, S.; Canonne, J.; Ben Khaled, S.; Khafif, M.; Pouzet, C.; Jauneau, A.; Roby, D.; Rivas, S. Arabidopsis ubiquitin ligase MIEL1 mediates degradation of the transcription factor MYB30 weakening plant defence. Nat. Commun. 2013, 10, 1475. [CrossRef]

17. Li, W.; Zhong, S.H.; Li, G.J.; Li, Q.; Mao, B.Z.; Deng, Y.W.; Zhang, H.J.; Zeng, L.J.; Song, F.M.; He, Z.H. Rice RING protein OsBBI1 with E3 ligase activity confers broad-spectrum resistance against Magnaporthe oryzae by modifying the cell wall defence. Cell Res. 2011, 21, 835-848. [CrossRef] [PubMed]

18. Zeng, D.E.; Hou, P.; Xiao, F.M.; Liu, Y.S. Overexpressing a novel RING-H2 finger protein gene, OsRHP1, enhances drought and salt tolerance in rice (Oryza sativa L.). J. Plant Biol. 2014, 57, 357-365. [CrossRef]

19. Park, Y.C.; Chapagain, S.; Jang, C.S. A Negative regulator in response to salinity in rice: Oryza sativa salt-, ABA- and droughtinduced RING finger protein 1 (OsSADR1). Plant Cell Physiol. 2018, 59, 575-589. [CrossRef]

20. Ryu, M.Y.; Cho, S.K.; Kim, W.T. The Arabidopsis C3H2C3-type RING E3 ubiquitin ligase AtAIRP1 is a positive regulator of an abscisic acid-dependent response to drought stress. Plant Physiol. 2010, 154, 1983-1997. [CrossRef] [PubMed]

21. Lu, F.L.; Li, G.L.; Cui, X.; Liu, C.Y.; Wang, X.J.; Cao, X.F. Comparative analysis of JmjC domain-containing proteins reveals the potential histone demethylases in Arabidopsis and rice. J. Integr. Plant Biol. 2008, 50, 886-896. [CrossRef]

22. Chen, X.S.; Hu, Y.F.; Zhou, D.X. Epigenetic gene regulation by plant Jumonji group of histone demethylase. Biochim. Biophys. Acta 2011, 1809, 421-426. [CrossRef] [PubMed]

23. Kabelitz, T.; Brzezinka, K.; Friedrich, T.; Gorka, M.; Graf, A.; Kappel, C.; Baurle, I. A JUMONJI protein with E3 ligase and histone $\mathrm{H} 3$ binding activities affects transposon silencing in Arabidopsis. Plant Physiol. 2016, 171, 344-358. [CrossRef]

24. Audonnet, L.; Shen, Y.; Zhou, D.X. JMJ24 antagonizes histone H3K9 demethylase IBM1/JMJ25 function and interacts with RNAi pathways for gene silencing. Gene Expr. Patterns 2017, 25, 1-7. [CrossRef] [PubMed]

25. Deng, S.L.; Jang, I.C.; Su, L.L.; Xu, J.; Chua, N.H. JMJ24 targets CHROMOMETHYLASE3 for proteasomal degradation in Arabidopsis. Genes Dev. 2016, 30, 251-256. [CrossRef] [PubMed]

26. Zhou, G.X.; Qi, J.; Ren, N.; Cheng, J.A.; Erb, M.; Mao, B.Z.; Lou, Y.G. Silencing OsHI-LOX makes rice more susceptible to chewing herbivores, but enhances resistance to a phloem feeder. Plant J. 2009, 60, 638-648. [CrossRef]

27. Lu, J.; Ju, H.P.; Zhou, G.X.; Zhu, C.; Erb, M.; Wang, X.; Wang, P.; Lou, Y.G. An EAR-motif-containing ERF transcription factor affects herbivore-induced signaling, defense and resistance in rice. Plant J. 2011, 68, 583-596. [CrossRef] [PubMed]

28. Lu, J.; Li, J.C.; Ju, H.P.; Liu, X.L.; Erb, M.; Wang, X.; Lou, Y.G. Contrasting effects of ethylene biosynthesis on induced plant resistance against a chewing and a piercing-sucking herbivore in rice. Mol. Plant 2014, 7, 1670-1682. [CrossRef] 
29. Li, R.; Zhang, J.; Li, J.C.; Zhou, G.X.; Wang, Q.; Bian, W.B.; Erb, M.; Lou, Y.G. Prioritizing plant defence over growth through WRKY regulation facilitates infestation by non-target herbivores. Elife 2015, 4, e04805. [CrossRef] [PubMed]

30. Hu, L.F.; Ye, M.; Li, R.; Lou, Y.G. OsWRKY53, a versatile switch in regulating herbivore-induced defense responses in rice. Plant Signal. Behav. 2016, 11, e1169357. [CrossRef]

31. Xu, J.; Wang, X.J.; Zu, H.Y.; Zeng, X.; Baldwin, I.T.; Lou, Y.G.; Li, R. Molecular dissection of rice phytohormone signaling involved in resistance to a piercing-sucking herbivore. New Phytol. 2021, 230, 1639-1652. [CrossRef] [PubMed]

32. Ye, M.; Kuai, P.; Hu, L.F.; Ye, M.F.; Sun, H.; Erb, M.; Lou, Y.G. Suppression of a leucine-rich repeat receptor-like kinase enhances host plant resistance to a specialist herbivore. Plant Cell Environ. 2020, 43, 2571-2585. [CrossRef]

33. Hao, P.Y.; Liu, C.X.; Wang, Y.Y.; Chen, R.Z.; Tang, M.; Du, B.; Zhu, L.L.; He, G.C. Herbivore-induced callose deposition on the sieve plates of rice: An important mechanism for host resistance. Plant Physiol. 2008, 146, 1810-1820. [CrossRef] [PubMed]

34. Liu, J.L.; Du, H.T.; Ding, X.; Zhou, Y.D.; Xie, P.F.; Wu, J.C. Mechanisms of callose deposition in rice regulated by exogenous abscisic acid and its involvement in rice resistance to Nilaparvata lugens Stal (Hemiptera: Delphacidae). Pest Manag. Sci. 2017, 73, 2559-2568. [CrossRef] [PubMed]

35. Zhou, Y.D.; Sun, L.T.; Wang, S.; Xie, P.F.; Liu, J.L. A key ABA hydrolase gene, OsABA8ox3 is involved in rice resistance to Nilaparvata lugens by affecting callose deposition. J. Asia-Pac. Entomol. 2019, 22, 625-631. [CrossRef]

36. Gao, W.; Liu, W.W.; Zhao, M.; Li, W.X. NERF encodes a RING E3 ligase important for drought resistance and enhances the expression of its antisense gene NFYA5 in Arabidopsis. Nucleic Acids Res. 2015, 43, 607-617. [CrossRef] [PubMed]

37. Ma, F.L.; Yang, X.F.; Shi, Z.Y.; Miao, X.X. Novel crosstalk between ethylene- and jasmonic acid-pathway responses to a piercingsucking insect in rice. New Phytol. 2020, 225, 474-487. [CrossRef] [PubMed]

38. Li, R.; Afsheen, S.; Xin, Z.J.; Han, X.; Lou, Y.G. OsNPR1 negatively regulates herbivore-induced JA and ethylene signaling and plant resistance to a chewing herbivore in rice. Physiol. Plant. 2013, 147, 340-351. [CrossRef]

39. Zhou, G.X.; Ren, N.; Qi, J.F.; Lu, J.; Xiang, C.Y.; Ju, H.P.; Cheng, J.A.; Lou, Y.G. The 9-lipoxygenase Osr9-LOX1 interacts with the 13-lipoxygenase-mediated pathway to regulate resistance to chewing and piercing-sucking herbivores in rice. Physiol. Plant. 2014, 152, 59-69. [CrossRef] [PubMed]

40. Hu, L.F.; Ye, M.; Li, R.; Zhang, T.F.; Zhou, G.X.; Wang, Q.; Lu, J.; Lou, Y.G. The Rice transcription factor WRKY53 suppresses herbivore-induced defenses by acting as a negative feedback modulator of mitogen-activated protein kinase activity. Plant Physiol. 2015, 169, 2907-2921. [CrossRef]

41. Li, J.C.; Liu, X.L.; Wang, Q.; Huangfu, J.Y.; Schuman, M.C.; Lou, Y.G. A Group D MAPK protects plants from autotoxicity by suppressing herbivore-induced defense signaling. Plant Physiol. 2019, 179, 1386-1401. [CrossRef] [PubMed]

42. Ye, W.X.; Adachi, Y.; Munemasa, S.; Nakamura, Y.; Mori, I.C.; Murata, Y. Open Stomata 1 kinase is essential for yeast elicitorinduced stomatal closure in Arabidopsis. Plant Cell Physiol. 2015, 56, 1239-1248. [CrossRef] [PubMed]

43. Oide, S.; Bejai, S.; Staal, J.; Guan, N.; Kaliff, M.; Dixelius, C. A novel role of PR2 in abscisic acid (ABA) mediated, pathogen-induced callose deposition in Arabidopsis thaliana. New Phytol. 2013, 200, 1187-1199. [CrossRef] [PubMed]

44. Yang, L.; Li, P.; Li, F.; Ali, S.; Sun, X.Q.; Hou, M.L. Silicon amendment to rice plants contributes to reduced feeding in a phloem-sucking insect through modulation of callose deposition. Ecol. Evol. 2018, 8, 631-637. [CrossRef] [PubMed]

45. Ding, X.; Huang, X.; Sun, L.T.; Wu, J.C.; Liu, J.L. Influence of abscisic acid-biosynthesis inhibitor fluridone on the feeding behavior and fecundity of Nilaparvata lugens. Insects 2019, 10, 57. [CrossRef]

46. Du, B.; Zhang, W.L.; Liu, B.F.; Hu, J.; Wei, Z.; Shi, Z.Y.; He, R.F.; Zhu, L.L.; Chen, R.Z.; Han, B.; et al. Identification and characterization of Bph14, a gene conferring resistance to brown planthopper in rice. Proc. Natl. Acad. Sci. USA 2009, 106, 22163-22168. [CrossRef] [PubMed]

47. Alamgir, K.M.; Hojo, Y.; Christeller, J.T.; Fukumoto, K.; Isshiki, R.; Shinya, T.; Baldwin, I.T.; Galis, I. Systematic analysis of rice (Oryza sativa) metabolic responses to herbivory. Plant Cell Environ. 2016, 39, 453-466. [CrossRef]

48. Liu, X.L. Functional Characterization of OsMPK4 in the Interaction of Rice with Insect Pests. Ph.D. Thesis, Zhejiang University, Zhejiang, China, 2018.

49. Wang, W.W.; Zhou, P.Y.; Mo, X.C.; Hu, L.F.; Jin, N.; Chen, X.; Yu, Z.X.; Meng, J.P.; Erb, M.; Shang, Z.C.; et al. Induction of defense in cereals by 4 -fluorophenoxyacetic acid suppresses insect pest populations and increases crop yields in the field. Proc. Natl. Acad. Sci. USA 2020, 117, 12017-12028. [CrossRef]

50. Yoshito, S.; Yoshito, S.; Kazushige, S. An ovicidal substance produced by rice plants in response to oviposition by the whitebacked planthopper, Sogatella furcifera (HORVATH) (Homoptera: Delphacidae). Appl. Entomol. Zool. 1996, 31, 467-473.

51. Zhou, P.Y.; Li, C.Z.; Wang, X.J.; Fu, W.J.; Wu, Y.T.; Lou, Y.G. Screening of chemical elicitors inducing the resistance of rice to the brown planthopper, Nilaparvata lugens (Hemiptera: Delphacidae). Acta Entomol. Sin. 2019, 62, 970-978.

52. Yoshida, S.; Forno, D.A.; Cock, J.H. Laboratory Manual for Physiological Studies of Rice, 3rd ed.; International Rice Research Institute: Manila, Philippines, 1976; pp. 1-83.

53. Huang, C.J.; Hu, G.J.; Li, F.F.; Li, Y.Q.; Wu, J.X.; Zhou, X.P. NbPHAN, a MYB transcriptional factor, regulates leaf development and affects drought tolerance in Nicotiana benthamiana. Physiol. Plant. 2013, 149, 297-309. [CrossRef]

54. Sun, Q.; Zhou, D.X. Rice jmjC domain-containing gene JMJ706 encodes H3K9 demethylase required for floral organ development. Proc. Natl. Acad. Sci. USA 2008, 105, 13679-13684. [CrossRef]

55. Whetstine, J.R.; Nottke, A.; Lan, F.; Huarte, M.; Smolikov, S.; Chen, Z.; Spooner, E.; Li, E.; Zhang, G.Y.; Colaiacovo, M.; et al. Reversal of histone lysine trimethylation by the JMJD2 family of histone demethylases. Cell 2006, 125, 467-481. [CrossRef] 
56. Xie, Q.; Guo, H.S.; Dallamn, G.; Fang, S.Y.; Weissman, A.M.; Chua, N.H. SINAT5 promotes ubiquitin-related degradation of NAC1 to attenuate auxin signals. Nature 2002, 419, 167-170. [CrossRef] [PubMed]

57. Zhang, Y.Y.; Yang, C.W.; Li, Y.; Zheng, N.Y.; Chen, H.; Zhao, Q.Z.; Gao, T.; Guo, H.S.; Xie, Q. SDIR1 is a RING finger E3 ligase that positively regulates stress-responsive abscisic acid signaling in Arabidopsis. Plant Cell 2007, 19, 1912-1929. [CrossRef] [PubMed]

58. Yang, L.; Chen, J.M.; Zhang, H.Q.; Zhang, J.F.; He, Y.P. Effects of brown planthopper Nilaparvata lugens Homoptera: (Stål) Delphacidae, feeding on callose deposition rice with different tolerance. Chin. J. Rice Sci. 2013, 27, 624-632.

59. Paguia, P.; Pathak, M.D.; Heinrichs, E.A. Honeydew excretion measurement techniques for determining differential feeding activity of biotypes of Nilaparvata lugens on rice varieties. J. Econ. Entomol. 1980, 73, 35-40. [CrossRef] 